\title{
Identification and Functional Characterization of von Willebrand Disease
}

\author{
Emmanuel J Favaloro, PhD
}

Professor, Department of Haematology, Institute of Clinical Pathology and Medical Research, Westmead Hospital, New South Wales

\begin{abstract}
The identification and functional characterization of von Willebrand disease (VWD) is challenging due to clinical uncertainty and limitations in test processes and panels used by laboratories, and because the classification scheme does not always permit unequivocal assignment of subtype. This article reviews contemporary alternatives to classic diagnostic approaches, including the incorporation of extended core test panels inclusive of the collagen-binding assay, and the potential for desmopressin (DDAVP) challenges not only to provide therapeutic information but also to assist the better characterization of individuals with defects or deficiencies in von Willebrand factor (VWF). supplementary assays such as the PFA-100 ${ }^{\circledR}$ and the VWF propeptide assay following DDAVP challenge are also worth considering.
\end{abstract}

\section{Keywords}

Desmopressin (DDAVP), von Willebrand factor (MWF), von Willebrand disease (MWD), diagnosis, classification

Disclosure: The authors have no conflicts of interest to declare.

Received: May 15, 2009 Accepted: June 21, 2009 DOI: 10.17925/OHR.2009.02.0.16

Correspondence: Emmanuel J Favaloro, PhD, Department of Haematology, Institute of Clinical Pathology and Medical Research (ICPMR), Westmead Hospital, NSW, Australia.

E: emmanuel.favaloro@swahs.health.nsw.gov.au

Von Willebrand disease (VWD) is the most common inherited bleeding disorder and is characterized by low levels of and/or abnormal function in the plasma protein von Willebrand factor (VWF). Typically, laboratory investigation entails initial plasma testing of factor VIII coagulant (FVIII:C), WWF protein antigen (VWF:Ag), and VWF activity, which is classically assessed using the ristocetin co-factor (VWF:RCo) assay. ${ }^{1-5}$ Newer tests of VWF function include the collagen-binding assay (VWF:CB) and other putative activity (VWF:Act) assays. ${ }^{2-6}$ Depending on initial test patterns and local availability, supplementary laboratory testing may also employ VWF multimers, ristocetin-induced platelet agglutination (or aggregation) (RIPA), VWF-FVIII binding (VWF:FVIIIB), and, in some cases, genetic analysis. ${ }^{1-7}$

Six types of VWD can be defined: types 1, 2A, 2B, 2M, 2N, and 3. ${ }^{1-7}$ Type 1 VWD is a partial quantitative defect and is simply defined by a reduction in plasma VWF; thus, the presenting VWF is essentially 'qualitatively normal.' Type 3 VWD is defined by (virtual) complete deficiency of VWF, and is diagnosed when there is essentially no measurable plasma VWF. Type 2 VWD defines qualitative defects of VWF. Type 2A VWD is defined by decreased VWF-dependent platelet adhesion and a selective deficiency of high-molecular-weight (HMW) VWF multimers, which can arise from either decreased production or increased plasma clearance. Type 2B VWD is defined by an increased affinity of VWF for its platelet receptor, glycoprotein Ib alpha (GPIb $\alpha$ ). This increased affinity typically (but not always) results in clearance of both HMW VWF and platelets from circulation, and thus (usually mild) thrombocytopenia. Type $2 \mathrm{~N}$ VWD is characterized by markedly decreased binding affinity of VWF for factor VIII, and presents phenotypically like hemophilia A. Type 2M VWD is defined by decreased VWF-dependent platelet adhesion without selective deficiency of HMW VWF multimers. In practice, type $2 \mathrm{M}$ VWD comprises a composite of different functional VWF defects and essentially any qualitative defect that cannot otherwise be characterized within other type 2 VWD groups. The most common type $2 \mathrm{M}$ VWD variants so far identified display defective binding of VWF to GPIb $\alpha$, but essentially (near) normal collagen binding.

\section{Laboratory Identification of von Willebrand Disease-Current Practice}

The correct diagnosis of VWD requires both clinical and laboratory evaluation and evidence. An appropriate clinical evaluation is critical, and includes an assessment of personal and familial history of bleeding/ bruising, evaluation of recent medication, and a physical examination. Appropriate laboratory evaluation is also critical, but is often lacking. There are limitations in the tests used by most laboratories, test panels are often incomplete, and interpretation of test data is often inadequate.

\section{Laboratory Tests Used for the Identification and Characterisation of von Willebrand Disease}

VWD is characterised by low levels of plasma VWF and/or abnormal VWF function. Ideally, a laboratory investigation would entail a panel of tests that would identify all possible presentations of VWD. Depending on 
local preferences, currently available test panels may include any combination of FVIII:C, VWF:Ag, VWF:RCo, VWF:CB, VWF:Act, VWF multimers, RIPA, VWF:FVIIIB, and genetic analysis. ${ }^{1-7}$ However, the actual tests, specific test methodologies, and their combinations, as used by individual laboratories, vary widely and this will influence, according to the specific investigation, the appropriate diagnosis and typing of VWD or its exclusion. In general, the more extensive the test panel and the more thorough the investigation, the more likely the correct identification and typing of VWD. Alternatively, the use of limited test panels or poor test methodologies will compromise test accuracy and result in a high likelihood of incorrect diagnoses. This will psychologically affect individuals and compromise their therapeutic management.

\section{von Willebrand Factor: Antigen}

This is the most often used test in the investigation of VWD. It is an immunological test that detects all forms of VWF equally well (i.e. functional, dysfunctional, and non-functional, high-, intermediate-, and low-molecular weight). This test should not be used alone as it has no differential sensitivity to identify VWD subtypes. VWF:Ag is most commonly performed as an enzyme-linked immunosorbent assay (ELISA), by enzyme-linked immunofluorescent assay (ELFA), or by automated immunoturbidimetric procedures such as latex-immunoassay (LIA). ELISA and ELFA assays suffer fewer technical problems, but require additional instrumentation and with a few exceptions (e.g. Vidas, bioMerieux) are unsuitable for urgent testing. LIA-based assays are suited to urgent testing, and can be performed using most modern coagulation analysers, but suffer from potential technical limitations (e.g. with testing of lipemic and icteric specimens, as well as falsely elevated values in the presence of rheumatoid factor). ${ }^{2} \mathrm{VWF}$ :Ag assays show moderate inter-assay or inter-laboratory variations ( 10-15\%), and LIA-based results tend to be slightly higher than those obtained by ELISA. ${ }^{2,6}$ Both ELISA and LIA methods show a lower limit of assay sensitivity of around $5-10 \mathrm{U} / \mathrm{dl} .^{8}$

\section{von Willebrand Factor: Ristocetin Co-factor}

This functional assay assesses the ability of VWF to bind to GPIb $\alpha$ in the presence of ristocetin, and is most commonly performed as a quantitative agglutination procedure using fixed or lyophilized platelets with an aggregometer or automated coagulation analyzer. ${ }^{2-6}$ This assay has the ability to preferentially identify HMW and intermediate-molecular-weight VWF, and so results tend to be lower than those of VWF:Ag when these VWF forms are lacking (i.e. types $2 \mathrm{~A}$ and $2 \mathrm{~B} V W D$ ). VWF:RCo is also lower than VWF:Ag when there is a specific defect in VWF binding to platelet GPIba (i.e. with some forms of type 2M VWD). Thus, the test combination of VWF:Ag and VWF:RCo should identify and partially distinguish all types of VWD but type $2 \mathrm{~N}^{2-6}$ with type 3 VWD showing an absence of VWF using both tests, type 1 VWD showing low but concordant test results with both tests, and types $2 \mathrm{~A}, 2 \mathrm{~B}$, and most $2 \mathrm{M}$ cases yielding proportionally lower VWF:RCo than VWF:Ag (typically referred to as VWF functional discordance). Unfortunately, VWF:RCo has a high inter-assay or interlaboratory variability of around $30-40 \%$, and a relatively high limit of assay sensitivity of around 15-20U/dl, which substantially limits its true utility in VWD diagnostics. ${ }^{2,4-6,8}$ In practice, this means that VWF:RCo often shows both poor accuracy and precision in the diagnostically critical region of $<20 \mathrm{U} / \mathrm{dl}$.

\section{von Willebrand Factor: Collagen-binding Assay}

These assays identify another functional property of VWF, namely its ability to bind to subendotheial matrix components, i.e. collagen in this case. Most commonly performed as an ELISA procedure, ${ }^{2-5}$ a welloptimized VWF:CB assay will demonstrate better preferential binding to HMW VWF than VWF:RCo, so that results tend to be lower than those of both VWF:Ag and VWF:RCo when there is an absence of HMW VWF forms (i.e. types $2 \mathrm{~A}$ and $2 \mathrm{~B} V \mathrm{VW}$ ). In theory, the test combination of VWF:Ag and VWF:CB should identify and partially distinguish all types of VWD but type $2 \mathrm{~N}$ and possible $2 \mathrm{M}$, with type 3 VWD showing an absence of VWF using both tests, type 1 showing low but concordant test results with both, and types $2 \mathrm{~A}$ and $2 \mathrm{~B}$ yielding proportionally less VWF:CB compared with VWF:Ag (i.e. evidence of VWF functional discordance). Nevertheless, VWF:CB assays are not surrogates for VWF:RCo, as both assays detect distinct functional properties of VWF, and therefore these should be utilized as complementary assays. VWF:CB has a moderate inter-assay or inter-laboratory variation of around $10-20 \%$, and a similar limit of assay sensitivity to VWF:Ag. ${ }^{2-5,8}$ such favorable technical features make the VWF:CB more practically 'useful' than the VWF:RCo assay in VWD diagnostics; however, there remains a significant lack of standardization, and because of inappropriate formulations most commercial VWF:CB assays do not preferentially recognize HMW VWF. ${ }^{2-5}$

\section{von Willebrand Factor: Activity}

This term refers to alternate (purported) activity assays for VWF, most of which utilize a monoclonal antibody to VWF, typically directed against a functional binding site. These assays are either ELISA- or LIA-based, and in fact are not true activity assays, although they may show some preferential binding to HMW VWF, and thus may yield discordant patterns compared with VWF:Ag when testing types 2A and 2B VWD. While their role in VWD diagnosis is largely unclear and evolving, ${ }^{2-6}$ they should not be used as surrogate assays for VWF:RCo.

\section{Factor VIII: Coagulant}

As VWF is the physiological carrier of FVIII in Vivo, FVIII:C testing is mandatory in the process of identification of VWD and will help guide further characterisation. FVIII:C is most commonly performed as a onestage clotting assay, although some laboratories use a chromogenic assay. Although FVIII:C will be approximately equal to or somewhat higher than the detected level of VWF in most individuals with VWD, FVIII:C levels cannot be easily predicted. A FVIII:C level lower than that of VWF may suggest either hemophilia A or type 2N VWD.

\section{von Willebrand Factor: Multimer Analysis}

This is a time-consuming and relatively skilled procedure that aims to identify the relative distribution of molecular-weight forms of VWF, as well as assessing qualitative defects of VWF multimer structure, but that few laboratories perform. Although of potential use in the diagnosis of VWD, the appropriate identification and characterization of the major proportion of VWD cases do not require multimer analysis.

\section{von Willebrand Factor: Factor VIIIB}

Performed to specifically identify type $2 \mathrm{~N}$ VWD and to distinguish this from hemophilia $A$, the assay is typically performed by ELISA and performed in parallel with a standard VWF:Ag ELISA assay. ${ }^{2}$ VWF:FVIIIB 
Table 1: Expected Laboratory Phenotypic von Willebrand Factor Assay Findings in von Willebrand Disease*

\begin{tabular}{|c|c|c|c|c|c|c|c|}
\hline Assay Parameter & & & & VWD Subtype & & & \\
\hline & 1 & $2 \mathrm{~A}$ & $2 \mathrm{~B}$ & $2 M(p)^{\star *}$ & $2 \mathrm{M}(\mathrm{c}) * *$ & $2 \mathrm{~N}$ & 3 \\
\hline WWF:Ag & Low (<50\%) & Low (/normal) & Low/normal & Low/normal & Normal (/low) & Low/normal & Absent \\
\hline WWF:RCo & Low (<50\%) & Low & Low & Low & Normal (/low) & Low/normal & Absent \\
\hline WWF:CB & Low (<50\%) & Low & Low & Low/normal & Low & Low/normal & Absent \\
\hline FVIII:C & Low (/normal) & Low (/normal) & Low (/normal) & Low (/normal) & Normal (/low) & Low & Very low $(<10 \%)$ \\
\hline $\mathrm{CB} / \mathrm{Ag}$ & Normal (>0.7) & Low (0-0.7) & Low (0-0.7) & Normal (>0.7) & Low (0-0.7) & Normal (>0.7) & NA \\
\hline $\mathrm{RCO} / \mathrm{Ag}$ & Normal (>0.7) & Low (0-0.7) & $\operatorname{Low}(0-0.7)$ & Low $(0-0.7)$ & Normal (>0.7) & Normal (>0.7) & NA \\
\hline FVIII/WWF & Normal (>0.7) & Normal (>0.7) & Normal (>0.7) & Normal (>0.7) & Normal (>0.7) & Low (0-0.7) & NA \\
\hline
\end{tabular}

*Absolute values noted in this table should be treated as a guide only; different laboratories utilize different values based on internal or differentially published studies. **Results in type $2 \mathrm{M}$ von Willebrand disease (VWD) depend on the specific mutation and defect defined. Most cases identified to date are platelet-binding dysfunctional ('2M (p)') and show low von Willebrand factor

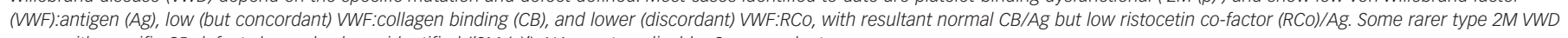
cases with specific $C B$ defects have also been identified ('2M (C)'). NA = not applicable; $C=$ coagulant.

assesses the ability of VWF to bind FVIII, and thus shows abnormal test results where there is a VWF-FVIII binding defect (i.e. type $2 \mathrm{~N}$ VWD). Thus, concordant levels of VWF:Ag and VWF:FVIIIB indicate normal FVIII binding and exclude type 2N VWD, whereas a proportionally low level of VWF:FVIIIB to VWF:Ag is indicative of type $2 \mathrm{~N}$ VWD. This assay is best performed by a VWD expert laboratory, not because the assay is difficult to perform but because its interpretation is problematic.

\section{Ristocetin-induced Platelet Agglutination}

Usually performed as part of a platelet function study, this assay involves challenging patient platelets with sequential concentrations of ristocetin. Responsiveness with low concentrations of ristocetin (typically $\leq 0.5 \mathrm{mg} / \mathrm{ml}$ ) is characteristic of type $2 \mathrm{~B}$ or pseudo (platelet-type [PT]) VWD. ${ }^{2,49}$ Alternately, a poor response to high concentrations of ristocetin (i.e. $>1.5 \mathrm{mg} / \mathrm{ml}$ ) would suggest (severe) type $1 \mathrm{VWD}$ or types $2 \mathrm{~A}$ or $2 \mathrm{M} \mathrm{VWD}$, whereas no response would suggest either type $3 \mathrm{VWD}$ or Bernard-Soulier Syndrome. Each of these alternate possibilities would require further study for a definitive diagnosis., 2,4,5

\section{Using Laboratory Tests to Identify and Characterise von Willebrand Disease Type 3 von Willebrand Disease}

Type 3 VWD is defined where plasma VWF is 'virtually' absent. In practice, the measured levels of plasma VWF (assayed by any VWF assay) should be $<5 \%$, although this may not always be apparent with some assays due to a lower limit of assay sensitivity (see Table 1). ${ }^{8}$ As plasma VWF protects and stabilizes FVIII:C, plasma levels of FVIII:C are also typically low, and usually also $<5 \%$. Type 3 VWD is a severe form of VWD, and patients may present clinically with a bleeding diathesis that resembles a combination of mucosal bleeding typical of VWD plus hemophilia A-like symptoms. The main difficulties with (mis)identification of type 3 VWD largely relate to inappropriate test panels, assay variation, and lower limit of sensitivity parameters.

\section{Type 1 von Willebrand Disease}

This is a quantitative disorder that presents with low levels of 'normalfunctioning' VWF. In practice, the presenting plasma levels of VWF would be similar, irrespective of the assay used to identify VWF (i.e. VWF:Ag, VWF:RCo, VWF:CB, or VWF:Act; see Table 1). Thus, the ratio of any VWF test to an alternate VWF test would be approximately 1.0 (in practice, the range of results will be in the region of $0.7-1.5)$. The severity of bleeding symptoms in type 1 VWD will correlate to the presenting level of plasma VWF. Our laboratory defines 'severe' type 1 VWD in individuals with less than $\sim 16 \%$ of normal plasma levels of VWF and 'moderate' type 1 VWD in those with levels between 16 and 35\% VWF. The concept of 'mild' type 1 VWD is contentious, and some will define individuals with plasma VWF from $~ 35 \%$ to the lower limit of the normal reference range as having 'mild' type $1 \mathrm{VWD}$, whereas others may identify these individuals as having a borderline-low VWF and, while recognizing such VWF 'deficiency' as a potential risk factor for bleeding, would not label these individuals as having VWD. In practice, VWF genetic defects are difficult to identify in individuals with presumed type I VWD where VWF levels exceed $35 \%$.

\section{Type 2 von Willebrand Disease}

This is a qualitative disorder, with individuals presenting with dysfunctional forms of VWF, with the type of dysfunction defining the VWD type.

\section{Type $2 A$ von Willebrand Disease}

This defines a specific deficiency of HMW VWF, and affected individuals will therefore present with relatively lower levels of VWF:RCo and VWF:CB than VWF:Ag (see Table 1). In general, this functional VWF discordance is defined by ratios of VWF:RCo/VWF:Ag (RCo/Ag) and VWF:CB/VWF:Ag (CB/Ag) below 0.7. ${ }^{1-6}$ Although VWF multimer analysis can confirm the loss of HMW VWF, in practice this is usually not required, and our own preference would be to perform a RIPA analysis and, if indicated, a DDAVP trial (as explained in later sections of this article).

\section{Type $2 B$ von Willebrand Disease}

This defines individuals with hyper-adhesive VWF, who will also typically present with relatively lower levels of VWF:RCo and VWF:CB compared with VWF:Ag, or functional VWF discordance (comparable to that for $2 \mathrm{~A}$ VWD) as defined by ratios of RCo/Ag and $\mathrm{CB} / \mathrm{Ag}$ below $\sim 0.7$. Although VWF multimer analysis can also be used to confirm the loss of HMW VWF, in practice again this is usually not required, and would not enable its differentiation from type 2A VWD. The definitive phenotypic test for identifying type 2B VWD is RIPA. Type 2B VWD can be distinguished from the phenotypically similar PT-VWD using RIPA-mixing studies or by specific genetic analysis of the VWF and platelet GPIb $\alpha$ genes. ${ }^{2,7,10,11}$

\section{Type $2 \mathrm{~N}$ von Willebrand Disease}

Type 2N VWF defines dysfunctional VWF to FVIII binding and individuals will present lower relative levels of plasma FVIII:C to VWF. 
Figure 1: Simplified Algorithm Describing a Possible Approach to Improving the Identification and Functional Characterization of von Willebrand Disease ${ }^{4}$

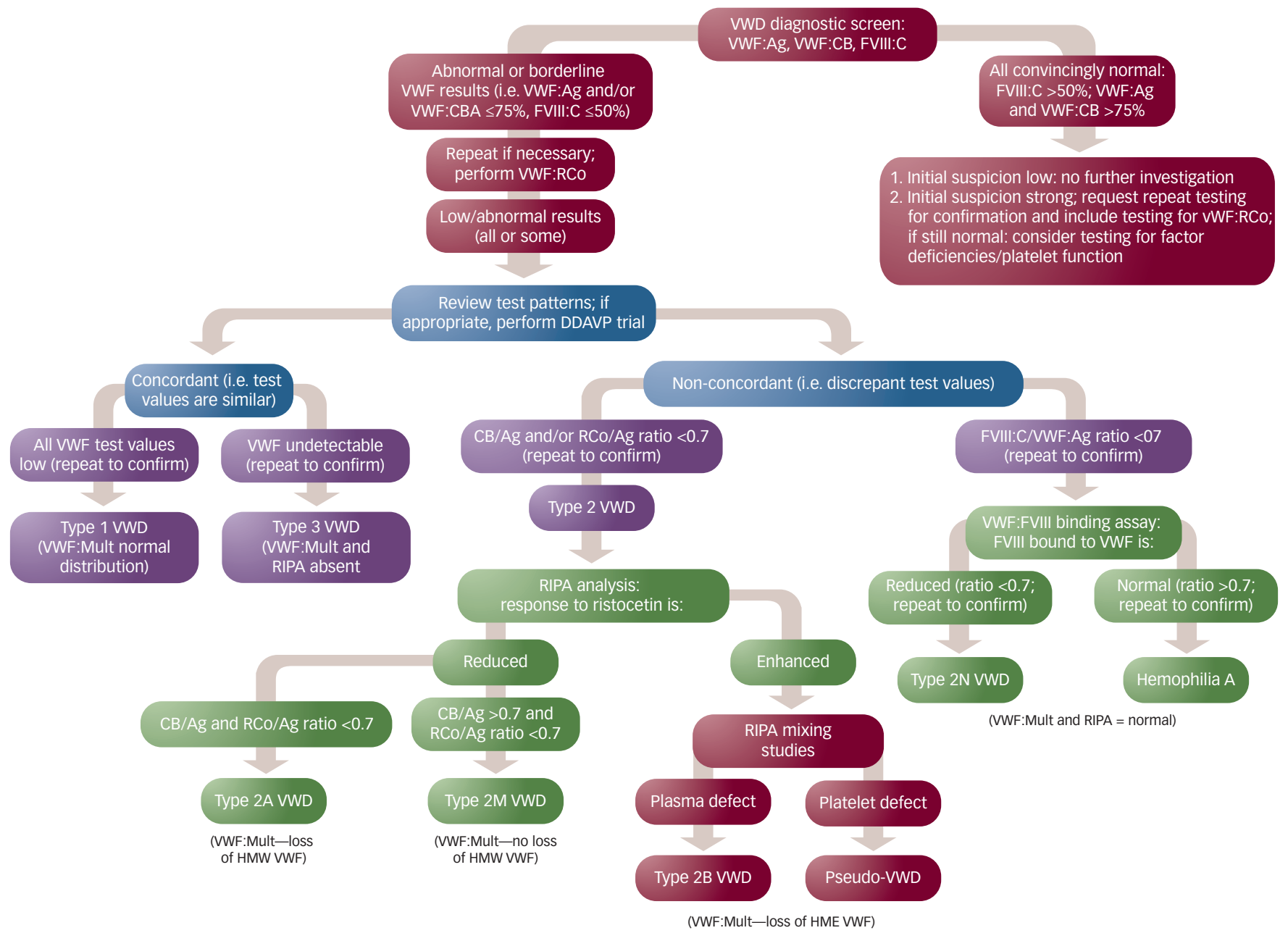

$V W D=$ von Willebrand disease; $V W F=$ von Willebrand factor; $A g=$ antigen; $R C O=$ ristocetin co-factor; $C B=$ collagen binding; $C=$ coagulant; $R I P A=$ ristocetin-induced platelet agglutination; DDAVP = desmopressin; Mult $=$ multimer.

The definitive phenotypic test for type $2 \mathrm{~N} V W D$, and to enable its discrimination from hemophilia $A$, is the VWF:FVIIIB assay, with genetic testing a feasible option. ${ }^{2,7}$

\section{Type $2 \mathrm{M}$ von Willebrand Disease}

Type 2M VWD comprises a variety of VWF defects, characterized by some dysfunction of VWF that does not fit within the other type 2 VWD categories. The majority of type $2 \mathrm{M}$ VWD cases so far described show a selective VWF to GPIba-binding defect without a corresponding collagen-binding defect. Accordingly, these tend to present with relatively lower VWF:RCo than VWF:Ag (or low RCo/Ag ratios), but relatively normal (or near normal) $\mathrm{CB} / \mathrm{Ag}$. However, a small number of type 2M VWD cases showing a collagen-binding defect (with relatively normal GPIb $\alpha$ binding) have been reported, ${ }^{1-3}$ and these will show the opposing discordance pattern, i.e. low relative $\mathrm{CB} / \mathrm{Ag}$ but normal (or near normal) RCo/Ag ratios.

A simplified algorithm highlighting the above patterns to permit a generalized means to identification and characterisation VWD can be seen in Figure 1. Our laboratory performs VWF:Ag, VWF:CB, and FVIII:C testing on all cases being evaluated for possible VWD. VWF:RCo testing is also performed where there is appropriate clinical evidence of significant muco-cutaneous bleeding, and/or when VWF:Ag and/or VWF:CB are $\leq 75 \%$. VWD (as we currently know it) can usually be excluded where VWF:Ag, VWF:CB, and FVIII:C are all $>75 \%$, as to date there have been no reported cases of VWD showing such a pattern.-5 However, a reasonable caveat here is that it is currently impossible to truly and entirely exclude VWD using any currently applicable test panel, given that we are unable to evaluate all possible VWF functions using current tests. Additional testing is warranted when VWF:Ag, VWF:CB, and/or FVIII:C test results are $\geq 75 \%$ and/or there is compelling clinical evidence of VWD-like bleeding symptoms. As shown in Figure 1, the subtype of VWD may then be surmised by the pattern of resultant test findings, as expanded elsewhere in this article.

\section{Evident Problems with Current Identification and Laboratory Diagnosis of von Willebrand Disease}

Given appropriate selection and application of test methodologies and panels, most cases of VWD will be appropriately identified and characterized. Nevertheless, the diagnosis of VWD remains 
problematic for a proportion of test cases due to the under-recognised heterogeneity of VWD and because of current test limitations. ${ }^{1-5,8,12}$ For example, many investigators ${ }^{6,8,12-23}$ have recently reported on diagnostic inconsistencies for VWD, including a series of genetic/phenotypic studies using samples derived from 'expert' VWD laboratories, ${ }^{13-16}$ which identified that between 15 and $33 \%$ of cases originally identified as type 1 VWD could be reclassified as type 2. Thus, a large number of type 2 VWD cases can be misidentified as type 1 VWD based on testing predominantly using a core three-test panel of FVIII, VWF:Ag, and VWF:RCo, even in VWD 'expert' laboratories. This situation mimics that identified by analysis of testing in 'real-world' laboratories comprising predominantly 'non-expert' pathology-based clinics, and where cases are derived from a mixed clinical referral base.,8,12,20-22 $\mathrm{A}$ similar matter regarding the misdiagnosis of type 1 VWD as type 2 VWD, and type 3 VWD as type 1 or type 2 VWD, or visa versa, can also be identified. $0^{6,8,12,20}$ Most misdiagnoses occur in these investigations either because of laboratory test panel limitations or because of misinterpretations of test findings.

Such misdiagnoses can have both therapeutic implications and psychological effects on affected patients. Although misdiagnoses and misclassifications have multiple causes, errors are in part likely due to the recognised limitations in the otherwise standard panel of VWF:Ag, VWF:RCO, and FVIII:C-6,8 as used by most laboratories for most investigations. This would include the previously mentioned assay limitations, including the lower test sensitivity limit, plus high relative assay variability or poor reproducibility, particularly for the VWF:RCo assay. It has also previously been identified that the addition of VWF:CB testing to such a test panel will consistently reduce error rates in VWD diagnosis. ${ }^{2-6,8,12}$ Additional examples related to the misdiagnosis of VWD, and explanatory reasons are provided elsewhere. ${ }^{4}$ In brief, type $2 \mathrm{~A}$, $2 \mathrm{M}$, and $2 \mathrm{~B}$ VWD are often misidentified as type $1 \mathrm{VWD}$ because discordance of VWF:RCo and VWF:Ag (or a low RCo/Ag ratio) is not always apparent in single testing, and type $1 \mathrm{VWD}$ is sometimes misidentified as type 2A or 2M VWD because false VWF functional discordance (i.e. false low RCo/Ag ratio) is sometimes identified. Occasionally, type 3 VWD is misidentified as type 1 or 2 VWD or hemophilia A. Interestingly, laboratories and clinicians sometimes misinterpret laboratory test data. ${ }^{12}$ Contrary to popular misconceptions, performance of multimer analysis is not a diagnostic panacea, although it is useful on occasion if performed appropriately. ${ }^{2-4}$ Indeed, in the real world of VWD testing, there is a high rate of errors associated with multimer testing., ${ }^{420}$ For example, data from the European Concerted Action on Thrombosis Foundation External Quality Assurance (ECAT/EQA) program have recently reported that laboratories will identify 'abnormal' multimer patterns including loss of HMW VWF in up to $20 \%$ of cases when testing normal plasma, and up to $50 \%$ of cases when testing a type 1 VWD sample. Thus, type 1 VWD samples were reported as type $2 \mathrm{~A}$ or $2 \mathrm{~B}$ in nearly $20 \%$ of test cases involving multimer analysis.

\section{Towards a New Paradigm to Better Define von Willebrand Disease} Expansion to a Comprehensive Test Panel that Includes the von Willebrand Factor: Collagen Binding Assay Due to diagnostic problems, laboratories and clinicians need additional strategies to ensure the appropriate identification of VWD.
In the 'real-world VWD testing' setting, the addition of a VWF:CB assay to the core three-test panel of FVIII, VWF:Ag, and VWF:RCo as typically used by most laboratories will substantially reduce the diagnostic error rate. For example, the misidentification of type 2 VWD as type 1 VWD can be reduced by $>50 \%$ (i.e. from a background of around $22 \%$ to typically $<10 \%) .{ }^{4,6,12}$ Use of a VWF:CB will also reduce the error rates associated with other types of VWD misdiagnoses. This is largely because optimized VWF:CB assays better discriminate HMW VWF, show a better lower limit of sensitivity, and have a lower inter-assay variability compared with standard VWF:RCo assays. Performance of VWF:CB testing can also negate the need to perform multimer analysis in many test cases. ${ }^{2-4,24,25}$ Unfortunately, some assay standardization concerns remain ${ }^{2-4}$ with broadly applied and commercially available VWF:CB assays that currently prevent the more universal translation of these findings.

\section{Use of Desmopressin Challenge to Help Identify von Willebrand Disease Subtypes}

Desmopressin (DDAVP) is a non-transfusional therapy often applied to individuals with VWD that acts to release endogenous (endothelial) stores of VWF. DDAVP is particularly useful for type 1 VWD, but can also be applied to some cases of type 2 VWD. Prior to its use for therapeutic need (e.g. surgery), it is usual to assess efficacy by undertaking a DDAVP trial or challenge because responsiveness differs from individual to individual and cannot otherwise be easily predicted. However, DDAVP responsiveness is fairly stable intra-individually, and hence a DDAVP challenge once undertaken can typically be used to predict future responsiveness from that same individual.

In addition to its therapeutic use, we and others have been interested in the potential use of DDAVP trials to help better functionally identify (using an extended test panel of FVIII:C, VWF:Ag, VWF:RCo, and VWF:CB) the VWD type of individuals, particularly those in which standard laboratory testing has failed to provide a definitive answer. ${ }^{26}$ Thus, in a large cross-laboratory, retrospective audit of DDAVP usage and effect, we could identify patterns that we believed to be VWD subtype discriminatory (summarized in Figure 2). For type 1 VWD, the classically reported patterns were generally evident, namely a substantial increase in FVIII:C and VWF post-DDAVP with some falls over time, so that near-baseline values are observed at 24 hours. Moreover, the largest increases were consistently observed for VWF:CB and FVIII:C (overshadowing rises in VWF:Ag and VWF:RCO). This was mirrored by high relative $\mathrm{CB} / \mathrm{Ag}$ versus $\mathrm{RCO} / \mathrm{Ag}$ ratios, reflective of ultra-large VWF release post-DDAVP, and explained in part by the higher comparative sensitivity of VWF:CB (compared with VWF:Ag and VWF:RCo) for detection of HMW VWF., ${ }^{2,3}$ Patients with type $2 \mathrm{~A}$ or $2 \mathrm{M} \mathrm{VWD}$ showed distinct patterns to each other and also to type 1 VWD, with evident rises in both VWF:Ag and FVIII:C, but differentially disparate rises in VWF:CB and/or VWF:RCo. In particular, distinctive patterns of behavior between type $2 \mathrm{~A}$ and $2 \mathrm{M}$ VWD were most obvious in terms of VWF:CB versus VWF:RCo, as well as relative assay-ratio data. Thus, type $2 \mathrm{~A}$ VWD cases tend to show similar and low-level rises in both $\mathrm{RCO} / \mathrm{Ag}$ and $\mathrm{CB} / \mathrm{Ag}$, with these tending to remain $<0.7$ at all time-points, whereas type $2 \mathrm{M}$ cases showed a distinctly unique pattern, with a good relative rise in $\mathrm{CB} / \mathrm{Ag}$ but not in $\mathrm{RCO} / \mathrm{Ag}$. 
Similar observations were reported by our laboratory for type 1 VWD over 10 years ago using a small number of patients within a single institution study, ${ }^{27}$ and have also been reported by other workers employing the same extended test panel. ${ }^{28-30} \mathrm{~A}$ large number of other studies have also reported on DDAVP responses in patients with VWD (recently reviewed by Nichols et al. ${ }^{31}$ ), but none of these has provided any differential data on VWF:CB versus VWF:RCo. However, perhaps of some specific interest are reports of DDAVP treatment in patients with type $2 \mathrm{~A}$ or $2 \mathrm{M}$ VWD, such as the recent report by Federici et al., ${ }^{32}$ where RCO/Ag ratios were low in all patients with type $2 \mathrm{~A}$ or $2 \mathrm{M}$ VWD before DDAVP, and did not change significantly post-DDAVP. Others have reported similar findings, but without performing the VWF:CB the discriminatory patterns we recently reported ${ }^{26}$ cannot otherwise be verified.

There have been a number of recent guidelines ${ }^{31,33,34}$ published on the diagnosis and management of VWD, and although all mention DDAVP therapy, current recommendations are to monitor primarily using the VWF:RCo assay. This author believes that existing data provide strong support for the incorporation of VWF:CB testing within this context; furthermore, use of the four-test panel noted previously (i.e. FVIII:C, VWF:Ag, VWF:CB, and VWF:RCo) will assist the future identification and functional characterisation of various patients with differing types of VWD, and the better discrimination of type 1,2A, and $2 \mathrm{M}$ VWD. In other words, use of this extended test panel will lessen the currently significant identification error rate otherwise obtained using the more limited but more often used test panel of FVIII:C, VWF:Ag, and VWF:RCO. ${ }^{3-6,12-23}$ Furthermore, this author believes that such findings will in time be proved to have clinically significant therapeutic implications, although this hypothesis remains untested.

\section{Using the PFA-100 ${ }^{\circledR}$ to Help Identify Functional von Willebrand Disease Subtypes}

The above process can be extended to utilize additional test parameters, such as the PFA-100® (Siemens, Marburg, Germany). ${ }^{35-38}$ In brief, the PFA-100 is very sensitive to the presence of plasma VWF, and accordingly is highly sensitive to VWD. The PFA-100 gives a single endpoint value called the closure time $(\mathrm{CT}),{ }^{36-38}$ and individuals with VWD provide prolonged CTs, in part according to the severity and type of VWD. Our laboratory reported many years ago in a small pilot study that in type 1 VWD, DDAVP tended to normalize all of the VWF test parameters (i.e. VWF:Ag, VWF:RCo, and VWF:CB), and also tended to correct the prolonged PFA-100 CT..$^{35}$ In contrast, in type 2A VWD DDAVP tended to normalize only VWF:Ag, but not the functional VWF test parameters (i.e. VWF:RCo and VWF:CB), and also failed to correct the prolonged PFA-100 CT. The working hypothesis at that time was that normalization of the PFA-100 required normalization of functional VWF.

As an extension to the previously noted study, ${ }^{26}$ an evaluation of the PFA-100 has also been recently undertaken in the context of DDAVP responsiveness, and in part as a follow-up to findings recently reported by others. ${ }^{39,40}$ It was found, using a larger number of VWD cases, that in type 1 VWD normalization of the PFA-100 CT was dependent on normalization of functional VWF, particularly that identified by the VWF:CB assay. ${ }^{41}$ In contrast, in type $2 \mathrm{~A}$ and $2 \mathrm{M}$ VWD normalization of the PFA-100 was rarely achieved, consistent with the usual finding that

\section{Figure 2: Summary of Discriminatory Post-desmopressin Changes in Hemophilia $A$ and in Types 1, 2A, and $2 \mathrm{M}$ von Willebrand Disease ${ }^{26,41}$}
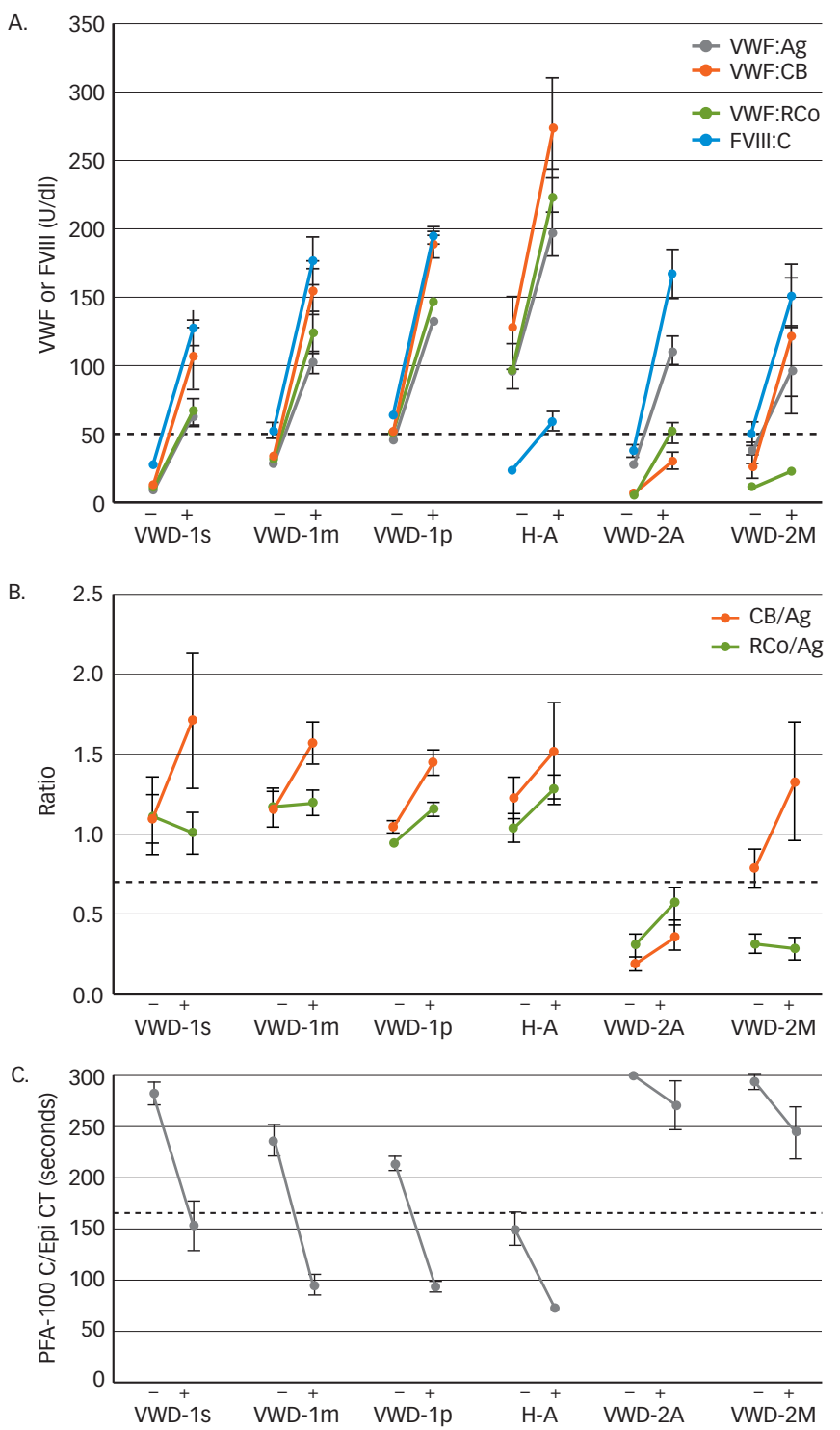

A: Pre- and post-desmopressin (DDAVP) values for factor VIII (FVIII):coagulant (C) and various VWF parameters. Dashed horizontal line indicates a nominal 'normal' cut-off value of 50U/dl. VWD-1S = 'severe' type 1 von Willebrand disease (VWD) patient group (baseline von Willebrand factor [VWF] values <16U/dl); VWD-1m = 'moderate' type $1 \mathrm{VWD}$ patient group (baseline VWF values 16-35U/dl); VWD-1p = 'possible mild' type 1 VWD patient group (baseline VWF values 36-65U/dl); $\mathrm{H}-\mathrm{A}=$ hemophilia $\mathrm{A}$ patient group; $V W D-2 A$ and $V W D-2 M=$ types $2 A W W D$ and $2 M$ VWD patient groups, respectively. B: Pre- and post-DDAVP ratios of collagen binding/antigen $(C B / A g)$ and ristocetin co-factor (RCo)/Ag for the same patient groups identified in A. Dashed horizontal line indicates a nominal 'normal' cut-off value of 0.7 as discriminatory for functional VWF discordance (i.e. $<0.7$ is suggestive of discordance, and may reflect a type 2 VWD pattern). C: Pre- and post-DDAVP PFA-100 ${ }^{\circledR}$ closure-times (CTS) for the same patient groups identified in A. Dashed horizontal line indicates the 'normal' cut-off value. In brief, type 1 VWD is typically characterized by correction of PFA-100 CTS (C) and good incremental rises in FVIII:C and all VWF test parameters, although rises in WWF:CB tend to exceed those of WWF:Ag and VWF:RCO (A) and, accordingly, rises in CB/Ag ratios may be observed, which tend to exceed RCo/Ag ratios (B). In contrast, type 2A VWD is typically characterized by non-correction of PFA-100 CTS (C) and good incremental rises in FVIII:C and VWF:Ag only (A); thus, CB/Ag and RCO/Ag both tend to remain low (B). Finally, platelet-binding dysfunctional type $2 M V W D$ is typically characterized by non-correction of PFA-100 CTS (C) and good incremental rises in FVIII:C, VWF:Ag, and VWF:CB (A); thus, only RCO/Ag tends to remain low (B).

correction of functional VWF also failed to occur. In total, the composite data (i.e. PFA-100 CT and plasma tests for VWFAg, VWF:RCo, VWF:CB, and 


\section{Figure 3: Toward a New Paradigm for the Identification and Functional Characterization of von Willebrand Disease ${ }^{4}$}

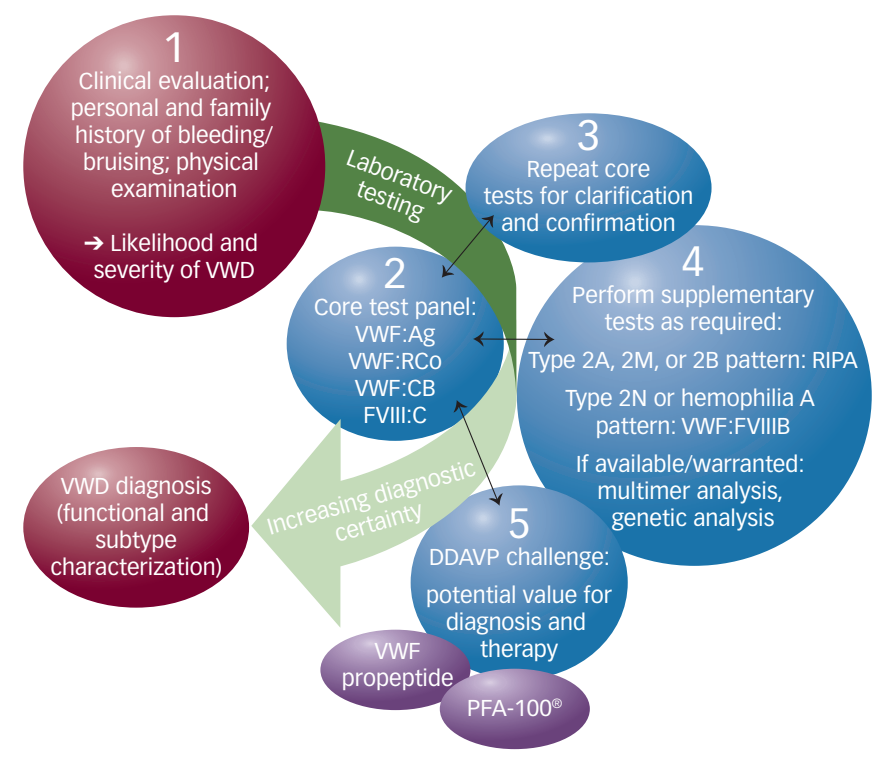

Schematic shows a progressive process for the characterisation of individuals with von Willebrand disease (VWD). With each step comes an increasing diagnostic certainty and a more comprehensive characterisation of that individual's VWD.

$V W F=$ von Willebrand factor; $A g=$ antigen; $R C O=$ ristocetin $c o$-factor; $C B=$ collagen-binding; $C=$ coagulant $;$ RIPA = ristocetin-induced platelet agglutination; $D D A V P=$ desmopressin .

FVIII:C) were considered to provide additional discriminatory power for the functional identification of VWD.

\section{Using the von Willebrand Factor Propeptide Assay to} Help Identify von Willebrand Disease Subtypes

Another assay that has been evaluated within the context of the functional characterisation of VWD during DDAVP therapy is the VWF propeptide (VWFpp) assay. Before de novo synthesized VWF leaves the endothelial cell, it undergoes endoproteolytic cleavage of its propeptide (VWFpp). The processed VWF and VWFpp are released either constitutively or, following activation of the endothelium, through a regulated pathway. Of interest, the plasma half-life of mature VWF and VWFpp differs several-fold (around eight to 12 and two to three hours, respectively). ${ }^{42}$ This property can be exploited to evaluate the potential for reduced VWF half-life or increased VWF clearance, which has been suggested as a pathogenic mechanism in some forms of VWD. In this context, it is usual to assess the relative elimination half-lives of either or both VWFpp and VWF post-DDAVP or to calculate VWFpp/VWF ratios, either at steady state or post-DDAVP.

For example, the VWFpp/VWF ratio has been shown to be dramatically increased in type vicenza VWD ${ }^{43}$ compared with normal subjects, whereas it is typically normal in most type 1 VWD patients, except for

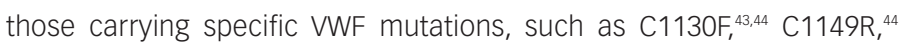
C2671Y, ${ }^{44}$ S2179F, ${ }^{45}$ and W1144G. ${ }^{45}$ Similarly, a very short half-life for VWF can be observed in type Vicenza VWD and patients carrying these specific VWF mutations, while most type 1 VWD patients are reported to have a half-life similar to that of normal individuals. ${ }^{43-46} \mathrm{~A}$ significant inverse correlation can be shown between VWFpp ratio and VWF half- life in both VWD patients and normal subjects. Accordingly, several workers have proposed that the VWFpp/VWF ratio is useful for distinguishing between type 1 VWD cases with a normal and a reduced VWF survival, as well as for identifying type Vicenza VWD.

The MCMDM-1VWD cohort have also reported on a group of type 1 VWD patients, and identified that a substantially increased ratio of steady-state VWFpp/VWF predicted a reduced VWF half-life in patients with markedly decreased VWF:Ag levels. They concluded that the systematic assay of both plasma VWF:Ag and VWFpp in moderately severe type 1 VWD patients may identify patients with a reduced VWF survival phenotype. ${ }^{47}$

However, the consistency of findings in patients with type 1 VWD has recently been questioned. ${ }^{48}$ Thus, although post-DDAVP clearance of VWF was increased by approximately three-fold in a type 1 VWD cohort overall, this was not shown to consistently associate with steady-state VWF:Ag levels. Furthermore, increased VWF clearance was not consistently associated with increased ratios of VWFpp/VWF, indicating that a normal ratio does not necessarily reflect normal post-DDAVP survival in type $1 \mathrm{VWD}$ patients. ${ }^{48}$ This may reflect complex heterogeneity in pathogenic mechanisms within type 1 VWD.

\section{Genetic Analysis in von Willebrand Disease Diagnosis}

There has been a recent explosion of genetic studies into VWD, including the previously mentioned studies into presumed type 1 VWD..$^{7,13-19}$ The generally increased awareness of genetic testing and its availability leads to the undesirable situation that clinicians, often keen to exploit newly developed tests to assist in the diagnosis of patients under their care, will request such tests at odds to their true clinical utility and cost- effectiveness. In general, although recent studies are invaluable in terms of furthering our understanding of $V W D$, there are several limitations when attempting to translate research findings into diagnostically useful test strategies.9,50 As the VWF gene is large and complex, genetic testing for VWD is not fool-proof and is typically expensive. VWD can arise from genetic events unrelated to the VWF gene, and the expression of VWF and the clinical severity in individual patients can be influenced by several epigenetic events. Currently, most of these additional complexities remain unknown.

In type $1 \mathrm{VWD}$, the search for a causative mutation may require an exhaustive and costly analysis of the entire gene, which will remain fruitless in nearly half of test cases. A significant proportion of type 1 VWD cases where a presumptive mutation is identified will also prove to be non-causal or 'innocent' polymorphisms. Thus, the search for mutations in the vast majority of presumptive type $1 \mathrm{VWD}$ investigations cannot be encouraged. The search for mutations in presumptive type 2 VWD cases will typically be more fruitful, but will still be clinically useful only in select cases where phenotypic testing has failed to provide diagnostic clarity. Excluding potential utility for pre-natal assessment in some cases of type 3 VWD, genetic investigations in type 3 VWD will otherwise also unlikely prove to be diagnostically or clinically useful. ${ }^{50}$ Readers are also encouraged to consider the views of experts in the field, inclusive of recent guidelines. ${ }^{7.51}$ 


\section{Conclusion}

Historically, the diagnosis of VWD can be seen as a dynamically evolving process, $^{52}$ beginning with the global tests of coagulation, several screening tests of platelet function that included the skin-bleeding time, and progression to detection of FVIII:C and VWF:Ag. During those years, the identification of VWD remained less than optimal. The next tests of significance to emerge were those based on ristocetin (VWF:RCo and RIPA), which appeared in the 1970s. Although these permitted a sort of revolution in the investigation of VWD, diagnosis remained problematic, given the poor reproducibility of the VWF:RCo and the poor sensitivity of RIPA for VWD. The VWF:CB was originally described in 1986, and although now over 21 years old, it still has to mature into a universally useful assay, largely because of standardization matters. ${ }^{3}$ Interestingly, several international mutational VWD studies, which were expected to provide some definitive answers regarding phenotype-genotype correlations in VWD, have instead shown a greater complexity within VWD than previously recognized, and have also highlighted significant error rates in the diagnosis and classification of VWD among expert laboratories. ${ }^{23}$ Errors within the real world of VWD investigation continue to cause misidentification of type 2 VWD as type 1 or 3 VWD, misidentification of type 1 VWD as type 2 or type 3 VWD, and misidentification of type 3 VWD as type 1 or 2 VWD or even hemophilia A. ${ }^{12}$ Many of these errors occur because of assay limitations and the use of limited test panels. In particular, VWF:RCo generally shows poor inter-assay and interlaboratory precision, and also the poorest lower limit of assay sensitivity.

The test combination of FVIII:C, VWF:Ag, and VWF:RCo is the most common test panel used worldwide for the identification, diagnosis, and classification of individuals with VWD, but experience tells us that an individual will be misdiagnosed in around $25 \%$ of occasions using this test panel. ${ }^{12,23}$ Adding a properly optimized VWF:CB assay to this test panel will substantially reduce error rates, with remaining errors often associated with misinterpretation of laboratory data rather than actual assay failures. ${ }^{12}$ Unfortunately, assay standardization issues prevent the proper universal worldwide adoption of VWF:CB assays, and it is doubtful that any commercial VWF:CB kit is currently truly fit for purpose. ${ }^{3}$

Accordingly, perhaps it is time to consider a paradigm shift to enable the appropriate diagnosis and functional characterisation of an individual's VWD, as depicted in Figure 3, and incorporating the use of a DDAVP challenge to identify functional changes in VWF over time. Combined use of the VWF:CB and VWF:RCo may better permit the differential functional characterisation of individuals with types $1,2 \mathrm{~A}$, or $2 \mathrm{M}$ VWD, and use of the VWFpp assay may permit the identification of individuals with reduced VWF survival. Finally, the potential use of the PFA-100 in this setting also warrants further investigation.

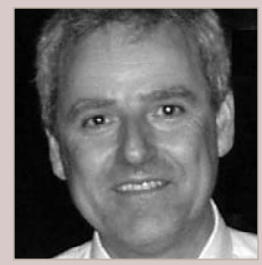

Emmanuel J Favaloro, PhD, is a Professor and Senior Scientist in charge of the hemostasis laboratories at the Institute of Clinical Pathology and Medical Research (ICPMR) at Westmead Hospital, part of the Sydney West Area Health Service. He has co-authored over 200 papers and is Editor in Chief for for Seminars in Thrombosis and Hemostasis. Professor Favaloro is also a Co-Chairman of the International Society on Thrombosis and Haemostasis (ISTH) Scientific Standardisation Committee (SSC) on von Willebrand factor (VWF), a member of the ISTH Working Party on coagulation standards, an Advisor to the Clinical and Laboratory Standards Institute (CLSI) Area Committee on Hematology and an advisory member of the Royal College of Pathologists of Australasia (RCPA) Haematology Quality Assurance Program (QAP) hemostasis committee. Professor Favaloro's primary interest is the diagnosis of bleeding and thrombotic disorders, particularly in von Willebrand disease and in developing and evaluating new or improved diagnostic processes.
1. Sadler JE, Budde U, Eikenboom JCJ, et al., J Thromb Haemost, 2006:4:2103-14.

2. Favaloro EJ, Semin Thromb Hemost, 2006;32:456-71.

3. Favaloro EJ, Semin Thromb Hemost, 2007;33:727-44.

4. Favaloro EJ, Semin Thromb Hemost, 2009;35:60-75.

5. Favaloro EJ. In: Preston E, Kitchen S, Olson JD (eds), Quality in Laboratory Hemostasis and Thrombosis, Oxford: Wiley-Blackwell, 2009;125-36.

6. Favaloro EJ, Bonar R, Meiring M, et al., Thromb Haemost, 2007;98:346-58

7. James P, Lillicrap D, Semin Thromb Hemost, 2008;34:502-8.

8. Favaloro $\mathrm{EJ}$, Bonar $\mathrm{R}$, Marsden $\mathrm{K}$ (on behalf of the RCPA QAP Haemostasis Committee), Clin Lab Sci, 2008;21: 178-85.

9. Duncan EM, Bonar R, Rodgers SE, et al., Int I Lab Hematol, 2008 (Epub ahead of print).

10. Favaloro EJ, Semin Thromb Hemost, 2008;34:113-27.

11. Othman M, Favaloro EJ, Semin Thromb Hemost, 2008;34: 520-31.

12. Favaloro EJ, Bonar R, Kershaw G, et al., RSemin Thromb Hemost, 2006;32:505-13

13. Goodeve A, Eikenboom J, Castaman G, et al., Blood, 2007;109:112-21.

14. James PD, Paterson $A D$, Notley $C$, et al., J Thromb Haemost, 2006;4:783-92

15. James PD, Notley $C$, Hegadorn $C$, et al., Blood, 2007:109:145-54

16. Cumming A, Grundy P, Keeney S, et al., Thromb Haemost, 2006:96:630-41.

17. Penas N, Pérez-Rodríguez A, Torea JH, et al., Am J Hematol, 2005:80:188-96

18. Riddell AF, Jenkins PV, Nitu-Whalley IC, et al., Br J Haematol,
2002;116: 187-92.

19. James PD, Notley $C$, Hegadorn $C$, et al., J Thromb Haemost, 2007:5:1914-22.

20. Meijer $P$, Haverkate F, Semin Thromb Hemost, 2006;32:485-91.

21. Kitchen $S$, Jennings I, Woods TA, et al., Semin Thromb Hemost, 2006;32:492-8.

22. Hayes TE, Brandt JT, Chandler WL, et al., Semin Thromb Hemost, 2006:32:499-504.

23. Favaloro EJ, I Thromb Haemost, 2008;6:1999-2001.

24. Adcock DM, Bethel $M$, Valcour $A$, Semin Thromb Hemost, 2006;32:472-9.

25. Meiring M, Badenhorst PN, Kelderman M, Clin Chem Lab Med, 2007:45:1068-72.

26. Favaloro EJ, Thom J, Patterson D, et al., Thromb Res, 2009;123:862-8.

27. Favaloro EJ, Dean M, Grispo L, et al., Am J Hematol, 1994:45:205-11.

28. Michiels JJ, van de Velde A, van Vliet HH, et al., Semin Thromb Hemost, 2002;28:111-32.

29. Michiels JJ, Berneman Z, Gadisseur A, et al., Clin Appl Thromb Hemost, 2006:12: 277-95.

30. Michiels JJ, van Vliet HH, Berneman Z, et al., Clin Appl Thromb Hemost, 2007:13:14-34.

31. Nichols WL, Hultin MB, James AH, et al., Haemophilia, 2008;14: 171-232.

32. Federici AB, Mazurier C, Berntorp E, et al., Blood, 2004;103:2032-8

33. Pasi KJ, Collins PW, Keeling DM, et al., Haemophilia, 2004;10:218-31.

34. Federici AB, Castaman G, Mannucci PM, Haemophilia, 2002;8:607-21.
35. Favaloro EJ, Kershaw G, Bukuya M, et al., Haemophilia, 2001;7: 180-89.

36. Favaloro EJ, Semin Thromb Hemost, 2006:32:537-45.

37. Favaloro EJ, Semin Thromb Hemost, 2006;6:566-76.

38. Favaloro EJ, Semin Thromb Hemost, 2008;34:709-33.

39. van Vliet HHDM, Kappers-Klunne MC, Leebeek FWG, et al., Thromb Haemost, 2008:100:462-8.

40. Favaloro EJ, Thromb Haemost, 2008:100:371-3.

41. Favaloro EJ, Thom J, Patterson D, et al., Blood Coag Fibrinolysis, 2009; in press.

42. Borchiellini A, Fijnvandraat K, ten Cate JW, et al., Blood, 1996:88:2951-8

43. Sztukowska M, Gallinaro L, Cattini MG, et al., Br J Haematol, 2008;143: 107-14

44. Schooten CJ, Tjernberg P, Westein E, et al., J Thromb Haemost, 2005;3:2228-37.

45. Haberichter SL, Balisteri M, Christopherson P, et al., Blood, 2006;108:3344-51.

46. Casonato A, Pontara E, Sartorello F, et al., Blood, 2002;99:180-84.

47. Haberichter SL, Castaman G, Budde U, et al., Blood, 2008;111:4979-85.

48. Millar CM, Riddell AF, Brown SA, et al., Thromb Haemost, 2008; 99:916-24.

49. Favaloro EJ, Thromb Haemost, 2009;102: in press.

50. Favaloro EJ, I Thromb Haemost, 2009 May 12 (Epub ahead of print)

51. Keeney S, Bowen D, Cumming A, et al., Haemophilia, 2008;14:1099-1111.

52. Koutts J, Semin Thromb Hemost, 2006:32:445-55. 